\title{
Diversity of Fruit Quality Characteristics in Capsicum frutescens
}

\author{
Robert L. Jarret ${ }^{1}$ \\ USDA/ARS/PGRCU, 1109 Experiment Street, Griffin, GA 30224 \\ Elizabeth Baldwin \\ USDA/ARS/CSPL, 600 Avenue NW, Winter Haven, FL 33881
}

\author{
Brian Perkins, Rod Bushway, and Kelly Guthrie \\ Department of Food Science and Human Nutrition, University of Maine, \\ Orono, ME 04469
}

Additional index words. plant germplasm, fruit morphology, organic acids, pungency, reducing sugars, Tabasco

\begin{abstract}
Fruit of 40 genotypes of Capsicum frutescens L. from the US Department of Agriculture/Agricultural Research Service Capsicum germplasm collection were analyzed for a variety of fruit quality parameters, including fruit size, weight, and concentrations of capsaicinoids, sucrose, glucose, fructose, malic acid, and total acid equivalents. Fruit weight ranged from $0.23 \mathrm{~g}$ fresh weight to $4.04 \mathrm{~g}$ fresh weight (average $1.05 \mathrm{~g}$ ). Fruit length/width ranged from 1 to 8.0 (average, 3.61). Capsaicin concentrations ranged from 34 to $350 \mathrm{mg} \cdot 100 \mathrm{~g}^{-1}$ fresh weight (average, $135 \mathrm{mg} \cdot 100 \mathrm{~g}^{-1}$ fresh weight). Sucrose concentrations ranged from 0.28 to $1.0 \mathrm{~g} \cdot 100 \mathrm{~g}^{-1}$ (average, $0.6 \mathrm{~g} \cdot 100 \mathrm{~g}^{-1}$ fresh weight). Total sugar extracts ranged from $0.73 \%$ to $2.6 \%$ (average, $1.55 \%$ ). Malic acid concentrations and total acid equivalents ranged from 0.62 to $2.29 \mathrm{~g} \cdot 100 \mathrm{~g}^{-1}$ fresh weight (average, $2.07 \mathrm{~g} \cdot 100 \mathrm{~g}^{-1}$ fresh weight) and 0.97 to $3.31 \mathrm{~g} \cdot 100 \mathrm{~g}^{-1}$ (average, $1.87 \mathrm{~g} \cdot 100 \mathrm{~g}^{-1}$ ) respectively. These data demonstrate an approximate 4 to 14-fold range in values for the characteristics examined, suggesting the presence of sufficient variability for these traits within this species to support the development of germplasm enhanced for specific or multiple fruit quality attributes.
\end{abstract}

Capsicum frutescens $\mathrm{L}$. is one of the five cultivated species in the genus Capsicum (Solanaceae) (Heiser and Pickersgill, 1969) and is closely related to $C$. chinense Jacq. (Baral and Bosland, 2004; Eshbaugh, 1976). Before Columbus, the neotropical range of $C$. frutescens extended from the Caribbean through northern South America (D'Arcy and Eshbaugh, 1974; Heiser and Smith, 1953). Numerous local land races of $C$. frutescens are cultivated in tropical and subtropical regions of the world (Heiser and Smith, 1953). The plants of C. frutescens are typically upright with one or sometimes two flowers per node, with green or greenish white corollas. Calyx teeth and a calyx constriction are lacking in $C$. frutescens. Fruit are typically upright, soft, and deciduous (D'Arcy and Eshbaugh, 1974).

C. frutescens is best known as the origin of the Tabasco variety of pepper, which has been grown commercially in the United States since the $1840 \mathrm{~s}$ for the production of Tabasco sauce (DeWitt and Bosland, 1996). This variety, originally introduced to Louisiana from Mexico, was replaced in the 1970 s by a tobacco etch virus-resistant cultivar (Greenleaf et al., 1970). Despite its

Received for publication 2 Jun. 2006. Accepted for publication 26 Jul. 2006.

${ }^{1}$ To whom reprint requests should be addressed; e-mail bjarret@ars-grin.gov from 53.08 to $73.44 \mathrm{mg} \cdot 100 \mathrm{~g}^{-1}$ and from 20.34 to $38.59 \mathrm{mg} \cdot 100 \mathrm{~g}^{-1}$ fresh weight respectively. Other fruit quality attributes, including concentrations of sucrose, fructose, and glucose, also affect fruit quality. The attribute sweetness was shown to be correlated with concentrations of sucrose and glucose in mature red fruit of $C$. annuum (Luning et al., 1994). The absence of sourness was similarly shown to be correlated with concentrations of various organic acids (Luning et al., 1994).

This study was undertaken to examine accessions of $C$. frutescens in the US Department of Agriculture/Agricultural Research Service Capsicum gene bank (Jarret et al., 1990) for variability of fruit composition attributes that might serve as the basis for efforts to enhance fruit quality.

\section{Materials and Methods}

Plant culture. Fifteen to 20 plants of each genotype (Table 1) were transplanted to and grown in the field on the Georgia Experiment Station campus (Griffin, Ga.) in May 2004. Plants received periodic fertilization and irrigation, as required. A minimum of 100 mature red fruit were collected from 10 plants per genotype in three consecutive harvests at 1 -week intervals (total of 300 fruit). In each instance, fruit were harvested from throughout the plants to reduce the effect of fruit position on the concentrations of the compounds to be analyzed (Zewdie and Bosland, 2000b). Variability in moisture content among fruit of accessions was determined to be $\approx 2 \%$. After harvest, fruit calyxes were removed and the fruit was counted, measured, weighed, and frozen at $-20^{\circ} \mathrm{C}$ for up to 2 weeks before extraction. Digital images of the plant materials used can be seen at www.ars-grin.gov.

Extraction of capsaicinoids. All 100 fruit from each sample were chopped into small $\left(<2.5 \mathrm{~mm}^{3}\right)$ pieces, and subsequently blended to a slurry using a commercial food processor. Five-gram aliquots of the fruit slurry were homogenized in $25 \mathrm{~mL} 100 \% \mathrm{MeOH}$ for $3 \mathrm{~min}$ in a $50-\mathrm{mL}$ centrifuge tube using a Tissumizer (Tekmar Corp., Cincinnati) homogenizer at speed setting 8 . The homogenate was centrifuged at $15,000 \mathrm{rpm}$ for 15 min at $20{ }^{\circ} \mathrm{C}$, and the supernatant containing total capsaicinoids was filtered through a syringe-mounted $22-\mu \mathrm{m}$ filter into amber vials and stored at $-4{ }^{\circ} \mathrm{C}$ for up to 2 weeks before analysis.

Extraction of carbohydrates and organic acids. Ten grams of fruit slurry were added to $40 \mathrm{~mL} 80 \% \mathrm{EtOH}$ and homogenized using a Tissumizer (Tekmar Corp.) homogenizer at speed setting 8 in a $250-\mathrm{mL}$ beaker. The homogenate was covered with a watch glass and was heated to boiling, with occasional stirring for $15 \mathrm{~min}$. The homogenate was transferred to a $250-\mathrm{mL}$ centrifuge bottle and was centrifuged for $10 \mathrm{~min}$ at $5000 \mathrm{rpm}$ at $25{ }^{\circ} \mathrm{C}$. The supernatant was brought to a final volume of $50 \mathrm{~mL}$ with $80 \% \mathrm{EtOH}$. For high-performance liquid chromatography 
Table 1. Variation in fruit weight, length, width, and length/width among fruit of 40 accessions of $C$. frutescens.

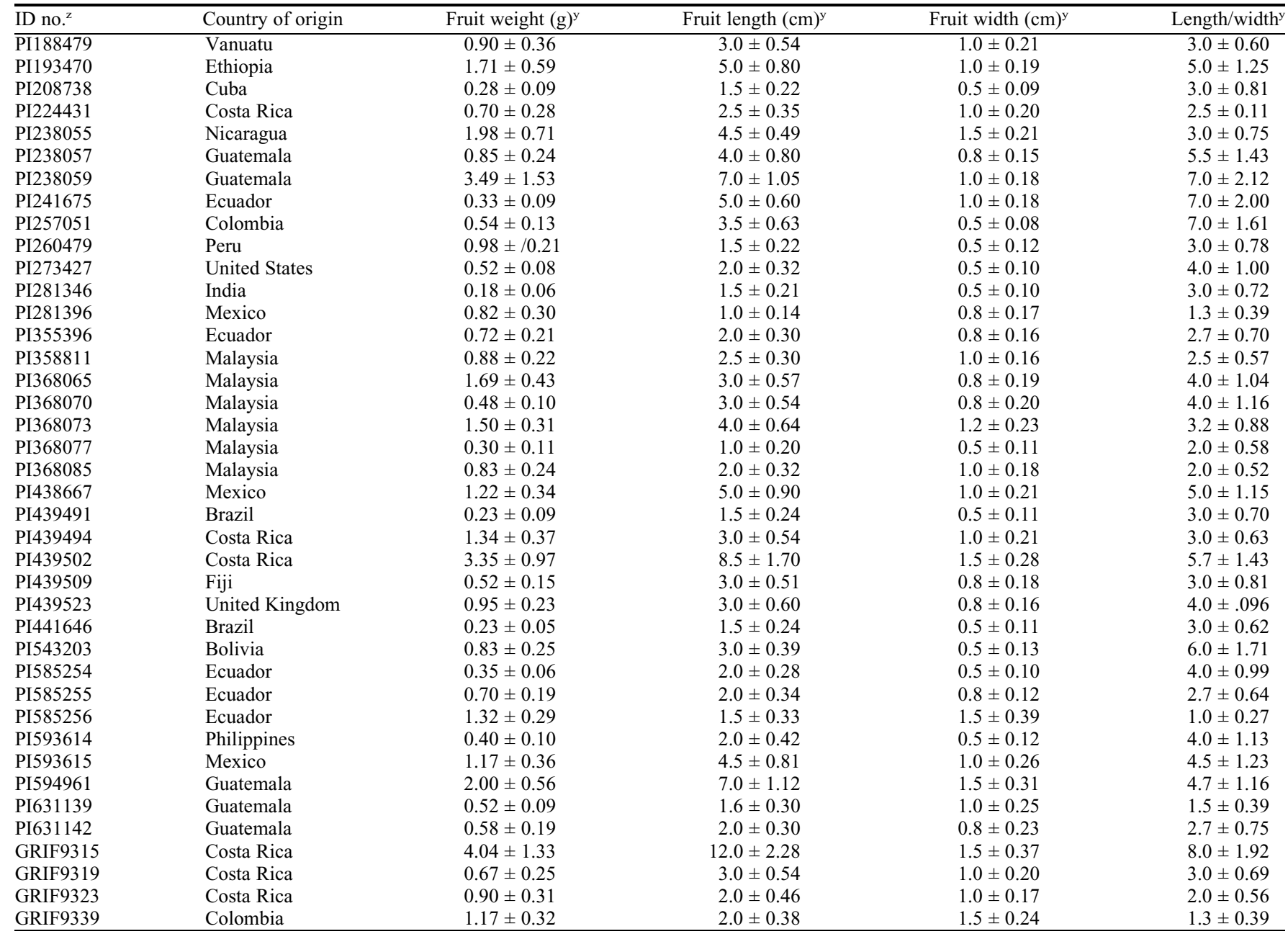

${ }^{2}$ Plant introduction (PI) numbers unless noted otherwise.

${ }^{\mathrm{y}}$ Mean $\pm \mathrm{SD}$

(HPLC) analysis, aliquots of this preparation were filtered sequentially through a preprepared Sep-Pak Plus C18 cartridge filter (Waters Corp., Milford, Mass.) and a 0.45$\mu \mathrm{m}$ syringe filter. Filtrates were stored in amber vials for up to 2 weeks at $-20{ }^{\circ} \mathrm{C}$ before analysis.

Analysis of capsaicinoids, carbohydrates, and organic acids. Capsaicin and dihydrocapsaicin were analyzed using HPLC as described previously (Jarret et al., 2003; Perkins et al., 2002). HPLC analysis of sugars was conducted as described by Baldwin et al. (1991). Individual sugars were analyzed by injecting $20 \mu \mathrm{L}$ extract filtrate on a Sugar Pak column at $90{ }^{\circ} \mathrm{C}$ (Waters, Millipore Corp., Milford, Mass.) with a mobile phase of $0.0001 \mathrm{~N}$ methylenediamine tetraacetic acid disodium-calcium salt (CaEDTA), a flow rate of $0.5 \mathrm{~mL} \cdot \mathrm{min}^{-1}$, and a refractive index detector (Agilent 1100 series; Agilent Technologies, Palo Alto, Calif.).

HPLC analysis of acids was conducted by injecting $20 \mu \mathrm{L}$ extract filtrate on a ThermoFinnigan SpectraSytem UV6000UL (Thermo Electron Corp., San Jose, Calif.) with a Prevail Organic Acid column at $35^{\circ} \mathrm{C}$ (Alltech, Deerfield, Ill.), a mobile phase of $0.1 \mathrm{~N}$
$\mathrm{H}_{2} \mathrm{SO}_{4}$, a flow rate of $0.2 \mathrm{~mL} \cdot \mathrm{min}^{-1}$, and a photo diode array (Thermo Electron Corp.) spectrophotometric detector at $210 \mathrm{~nm}$.

\section{Results and Discussion}

Fruit size and shape were highly variable in C. frutescens (Table 1). Fruit weight averaged $1.05 \mathrm{~g}$ fresh weight with a range of $0.18 \mathrm{~g}$ fresh weight (PI 281346) to $4.04 \mathrm{~g}$ fresh weight (GRIF 9315) with an average of $1.05 \mathrm{~g}$ fresh weight. Zewdie and Zeven (1997) noted a 5.5-fold variation in fruit weight among 67 pungent varieties of $C$. annuum from Yugoslavia. We observed that fruit length varied from $1 \mathrm{~cm}$ (PI 368077 and PI 281396) to $8.5 \mathrm{~cm}$ (PI 439502). Most fruit were clearly elongate. However, the fruit length-to-width ratio varied from 1.0 (PI 585256) to 7 (PI 238059) with an average of 3.6.

Total capsaicinoids (capsaicin plus dihydrocapsaicin) content among the $C$. frutescens accessions varied by approximately ninefold from 53 (PI 439502 to 456 (PI 241675) $\mathrm{mg} / 100 \mathrm{~g}$ fresh weight (Table 2). Values for the individual capsaicinoids (capsaicin and dihydrocapsaicin) ranged from
35 (PI 439502) to 350 (PI 241675) mg/100 g fresh weight and 18.5 (PI 439502) to 105 (PI 241675) $\mathrm{mg} / 100 \mathrm{~g}$ fresh weight respectively. However, the ratio of capsaicin to dihydrocapsaicin averaged 2.94 and ranged from 0.94 (PI 594961) to 7.05 (PI 543203). Zewdie and Bosland (2001) noted an average capsaicin-to-dihydrocapsaicin ratio of 2:1 among 10 accessions of $C$. frutescens. Although capsaicin is typically the predominant capsaicinoid in hot peppers, the ratio of capsaicin to dihydrocapsaicin can vary substantially within and among species (Zewdie and Bosland, 2001). The individual capsaicinoids vary in their sensory properties (Krajewska and Powers, 1988), thus affecting the overall taste and degree of pungency. In addition to large genotypic effects on pungency, a portion of the variability in the observed capsaicinoid values may reflect the relative proportions of placental tissue to the total fruit mass, stage of maturation (Contreras-Padilla and Yahia, 1998), and local environment (Harvell and Bosland, 1997). As reported by Iwai et al. (1979), capsaicinoid synthesis and accumulation are restricted to the placental tissues. 
Table 2. Variation in fruit concentrations of capsaicin (CAP), dihydrocapsaicin (DHC), and total capsaicinoids (TC) in milligrams per $100 \mathrm{~g}$ fresh weight, and the ratio of capsaicin to dihydrocapsaicin (C/D) in 40 genotypes of $C$. frutescens.

\begin{tabular}{|c|c|c|c|c|}
\hline$\overline{\text { ID no. }}{ }^{\mathrm{z}}$ & CAP $^{y}$ & $\mathrm{DHC}^{\mathrm{y}}$ & $\mathrm{TC}^{\mathrm{y}}$ & $\mathrm{C} / \mathrm{D}$ \\
\hline$\overline{\text { PI188479 }}$ & $121.9 \pm 7.1$ & $52.2 \pm 3.4$ & $174.1 \pm 10.5$ & 2.3 \\
\hline PI193470 & $60.8 \pm 4.2$ & $36.0 \pm 2.1$ & $96.8 \pm 6.3$ & 1.7 \\
\hline PI208738 & $272.4 \pm 11.3$ & $94.6 \pm 4.1$ & $367.1 \pm 15.4$ & 2.9 \\
\hline PI224431 & $71.3 \pm 2.9$ & $37.5 \pm 2.3$ & $108.8 \pm 5.2$ & 1.9 \\
\hline PI238055 & $95.8 \pm 3.4$ & $38.9 \pm 3.2$ & $134.7 \pm 6.6$ & 2.5 \\
\hline PI238057 & $124.1 \pm 4.6$ & $59.0 \pm 2.9$ & $183.1 \pm 7.5$ & 2.1 \\
\hline PI238059 & $64.2 \pm 2.7$ & $28.3 \pm 1.5$ & $92.5 \pm 4.2$ & 2.3 \\
\hline PI241675 & $351.6 \pm 16.0$ & $105.1 \pm 3.3$ & $456.7 \pm 19.3$ & 3.3 \\
\hline PI257051 & $166.6 \pm 6.7$ & $42.6 \pm 3.8$ & $209.3 \pm 10.5$ & 3.9 \\
\hline PI260479 & $312.8 \pm 12.2$ & $78.8 \pm 5.2$ & $391.6 \pm 17.4$ & 4.0 \\
\hline PI273427 & $100.6 \pm 4.1$ & $29.8 \pm 2.2$ & $130.3 \pm 6.3$ & 3.4 \\
\hline PI281346 & $114.3 \pm 4.9$ & $31.2 \pm 1.5$ & $145.5 \pm 6.4$ & 3.7 \\
\hline PI281396 & $110.9 \pm 3.8$ & $28.9 \pm 1.4$ & $139.8 \pm 5.2$ & 3.8 \\
\hline PI355396 & $78.9 \pm 2.9$ & $24.1 \pm 1.5$ & $102.9 \pm 4.4$ & 3.3 \\
\hline PI358811 & $88.4 \pm 3.6$ & $28.8 \pm 1.7$ & $91.3 \pm 5.3$ & 3.1 \\
\hline PI368065 & $162.1 \pm 5.1$ & $41.9 \pm 1.8$ & $204.0 \pm 6.9$ & 3.9 \\
\hline PI368070 & $157.3 \pm 5.5$ & $49.4 \pm 2.1$ & $206.7 \pm 7.6$ & 3.2 \\
\hline PI368073 & $84.9 \pm 4.1$ & $33.8 \pm 1.9$ & $118.7 \pm 6.0$ & 2.5 \\
\hline PI368077 & $97.4 \pm 3.9$ & $29.5 \pm 1.6$ & $126.9 \pm 5.5$ & 3.3 \\
\hline PI368085 & $115.8 \pm 3.7$ & $52.1 \pm 2.5$ & $167.9 \pm 6.2$ & 2.2 \\
\hline PI438667 & $145.5 \pm 4.6$ & $49.1 \pm 2.1$ & $194.6 \pm 6.7$ & 2.9 \\
\hline PI439491 & $231.6 \pm 8.8$ & $59.9 \pm 2.1$ & $291.5 \pm 10.9$ & 3.9 \\
\hline PI439494 & $87.5 \pm 2.3$ & $36.6 \pm 1.2$ & $124.0 \pm 3.5$ & 2.4 \\
\hline PI439502 & $34.9 \pm 1.6$ & $18.5 \pm 0.9$ & $53.5 \pm 2.5$ & 1.9 \\
\hline PI439509 & $216.7 \pm 7.7$ & $5.1 \pm 3.3$ & $281.8 \pm 11.0$ & 3.3 \\
\hline PI439523 & $112.5 \pm 3.8$ & $49.6 \pm 2.1$ & $162.1 \pm 5.9$ & 2.3 \\
\hline PI441646 & $317.6 \pm 10.1$ & $80.5 \pm 3.9$ & $398.2 \pm 14.0$ & 3.9 \\
\hline PI543203 & $174.4 \pm 6.1$ & $24.7 \pm 1.0$ & $199.1 \pm 7.1$ & 7.0 \\
\hline PI585254 & $130.2 \pm 3.7$ & $42.2 \pm 1.7$ & $172.3 \pm 5.4$ & 3.1 \\
\hline PI585255 & $208.9 \pm 6.7$ & $83.8 \pm 2.2$ & $292.8 \pm 8.9$ & 2.5 \\
\hline PI585256 & $84.2 \pm 3.4$ & $30.5 \pm 1.0$ & $114.8 \pm 4.4$ & 2.7 \\
\hline PI593614 & $161.3 \pm 3.7$ & $44.0 \pm 1.4$ & $205.4 \pm 5.1$ & 3.6 \\
\hline PI593615 & $91.5 \pm 3.8$ & $53.4 \pm 2.2$ & $144.9 \pm 6.0$ & 1.7 \\
\hline PI594961 & $45.4 \pm 2.3$ & $48.5 \pm 2.1$ & 93. \pm 94.4 & 0.9 \\
\hline PI631139 & $160.2 \pm 3.9$ & $50.9 \pm 2.5$ & $211.1 \pm 6.4$ & 3.1 \\
\hline PI631142 & $9.2 \pm 3.0$ & $23.4 \pm 1.3$ & $102.6 \pm 4.3$ & 3.4 \\
\hline GRIF9315 & $54.1 \pm 4.2$ & $36.5 \pm 1.3$ & $90.7 \pm 5.5$ & 1.5 \\
\hline GRIF9319 & $137.1 \pm 6.7$ & $40.5 \pm 1.8$ & $177.6 \pm 8.5$ & 3.4 \\
\hline GRIF9323 & $117.2 \pm 4.8$ & $38.2 \pm 1.6$ & $155.4 \pm 6.4$ & 3.1 \\
\hline GRIF9339 & $67.7 \pm 2.7$ & $44.0 \pm 1.7$ & $111.7 \pm 4.4$ & 1.5 \\
\hline
\end{tabular}

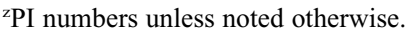

${ }^{\mathrm{y}}$ Mean $\pm \mathrm{SD}$.

Sucrose concentrations in fruit homogenates ranged from 0.28 (PI 543203) to 1.0 (PI 439509) $\mathrm{g} / 100 \mathrm{~g}$ fresh weight with an average of $0.6 \mathrm{~g} / 100 \mathrm{~g}$ fresh weight (Table 3 ). Glucose and fructose concentrations ranged from 0.43 (PI 358811) to 2.78 (PI 238055) $\mathrm{g} / 100 \mathrm{~g}$ fresh weight and 0.63 (PI 631142) to 3.48 (PI 543203 ) g/100 g fresh weight respectively. Concentrations of total sugars were highest in GRIF 9315 (6.84 g/100 g fresh weight) and lowest $(1.84 \mathrm{~g} / 100 \mathrm{~g}$ fresh weight) in PI358811 and PI631142. These values are in general agreement with those reported by Luning et al. (1994) and Lopez-Hernandez et al. (1996), who demonstrated that concentrations of these sugars, and dry matter content, were related to the attribute sweetness in fully mature fruit of C. annuum.

Concentrations of organic acids were shown to be negatively correlated with sourness in mature fruit of $C$. annuum cvs. (Luning et al., 1994). Among the C. frutescens accessions examined, malic acid concentrations ranged from 0.62 (PI 238059) to 2.29 (PI 439494) $\mathrm{g} / 100 \mathrm{~g}$ fresh weight with an average of $1.61 \mathrm{~g} / 100 \mathrm{~g}$ fresh weight (Table 3 ). Total acid equivalents ranged from 0.86
(PI 631142) to 3.31 (PI 543203) with an average of 1.85 .

\section{Conclusion}

Although a variety of compounds are known to affect the flavor (sweetness, sourness, pungency, etc.) and health-promoting benefits (vitamins, antioxidants, minerals, etc.) of pepper (Capsicum spp.) fruit, the scientific literature contains relatively little information on the extent of variability within the Capsicum germplasm for these characteristics. Information on fruit quality attributes can facilitate the development of varieties specifically enhanced for these characteristics by identifying genotypes to serve as potential parents in breeding programs, or for use in related research. The data reported here suggest that sufficient variability for fruit quality characteristic exists within the C. frutescens germplasm to support the development of varieties with specific flavor attributes.

\section{Literature Cited}

Baldwin, E.A., M.O. Nisperos-Carriedo, R. Baker, and J.W. Scott. 1991. Quantitative analysis of flavor parameters in six Florida tomato cultivars (Lycopersicon esculentum Mill). J. Agr. Food Chem. 39:1135-1140.

Baral, J.B. and P.W. Bosland. 2004. Unraveling the species dilemma in Capsicum frutescens and C. chinense (Solanaceae): A multiple evidence approach using morphology, molecular analysis, and sexual compatibility. J. Amer. Soc. Hort. Sci. 129:826-832.

Contreras-Padilla, M. and E.M. Yahia. 1998 Changes in capsaicinoids during development, maturation, and senescence of chile peppers and relation with peroxidase activity. J. Agr. Food Chem. 46:2075-2079.

D'Arcy, W.G. and W.H. Eshbaugh. 1974. New World peppers (Capsicum - Solanaceae) North of Colombia: A resume. Baileya 19:93-105.

DeWitt, D. and P.W. Bosland. 1993. The pepper garden. Ten Speed Press, Berkeley, Calif.

DeWitt, D. and P.W. Bosland. 1996. Peppers of the world: An identification guide. Ten Speed Press, Berkeley, Calif.

Duke, S.O., K.K. Schrader, D.E. Wedge, F.H. Arthur, D.H. Akey, M.R. Tellez, F.E. Dayan, S.R. Baerson, B.E. Scheffler, A.M. Rimando, A.J. DeLucca, D.M. Gibson, H.F. Harrison, J.K. Peterson, D.R. Gealy, T. Tworkoski, C.L. Wilson, and J.B. Morris. 2003. United States Department of Agriculture-Agricultural Research Service. Natural products for pest management. Pest Man. Sci. 59:708-717. 
Table 3. Variation (mean $\pm \mathrm{SD}$ ) in fruit concentrations of sucrose $(\mathrm{S})$, glucose $(\mathrm{G})$, fructose (F), malic acid (MA), and total acid equivalents (TAE) in 40 genotypes of $C$. frutescens.

\begin{tabular}{|c|c|c|c|c|c|}
\hline$\overline{\text { ID no. }}{ }^{z}$ & $\mathrm{~S}$ (g/100 $\mathrm{g}$ fresh weight) & $\mathrm{G}$ (g/100 g fresh weight) & $\mathrm{F}$ (g/100 $\mathrm{g}$ fresh weight) & MA (g/100 g fresh weight) & TAE (\%) \\
\hline$\overline{\text { PI188479 }}$ & $0.45 \pm 0.004$ & $2.13 \pm 0.17$ & $2.00 \pm 0.18$ & $2.07 \pm 0.12$ & $2.19 \pm 0.08$ \\
\hline PI193470 & $0.78 \pm 0.022$ & $1.95 \pm 0.19$ & $2.28 \pm 0.16$ & $0.94 \pm 0.06$ & $2.46 \pm 0.13$ \\
\hline PI208738 & $0.68 \pm 0.016$ & $1.08 \pm 0.10$ & $1.10 \pm 0.04$ & $1.96 \pm 0.05$ & $1.35 \pm 0.08$ \\
\hline PI224431 & $0.45 \pm 0.011$ & $0.88 \pm 0.07$ & $0.80 \pm 0.04$ & $1.90 \pm 0.10$ & $0.99 \pm 0.10$ \\
\hline PI238055 & $0.58 \pm 0.012$ & $2.78 \pm 0.16$ & $2.40 \pm 0.15$ & $1.62 \pm 0.09$ & $2.71 \pm 0.16$ \\
\hline PI238057 & $0.68 \pm 0.016$ & $2.48 \pm 0.17$ & $2.33 \pm 0.13$ & $1.87 \pm 0.13$ & $2.61 \pm 0.12$ \\
\hline PI238059 & $0.43 \pm 0.013$ & $1.97 \pm 0.12$ & $2.35 \pm 0.13$ & $0.62 \pm 0.08$ & $2.38 \pm 0.17$ \\
\hline PI241675 & $0.45 \pm 0.011$ & $1.25 \pm 0.10$ & $1.35 \pm 0.09$ & $1.51 \pm 0.07$ & $1.48 \pm 0.11$ \\
\hline PI257051 & $0.55 \pm 0.012$ & $0.88 \pm 0.04$ & $1.10 \pm 0.06$ & $1.81 \pm 0.08$ & $1.24 \pm 0.07$ \\
\hline PI260479 & $0.70 \pm 0.019$ & $1.00 \pm 0.07$ & $1.15 \pm 0.08$ & $1.52 \pm 0.08$ & $1.37 \pm 0.08$ \\
\hline PI273427 & $0.65 \pm 0.012$ & $1.15 \pm 0.06$ & $1.30 \pm 0.08$ & $1.31 \pm 0.05$ & $1.50 \pm 0.10$ \\
\hline PI281346 & $0.85 \pm 0.013$ & $1.15 \pm 0.08$ & $1.03 \pm 0.07$ & $0.98 \pm 0.07$ & $1.39 \pm 0.09$ \\
\hline PI281396 & $0.75 \pm 0.015$ & $1.65 \pm 0.07$ & $1.58 \pm 0.11$ & $1.90 \pm 0.08$ & $1.88 \pm 0.06$ \\
\hline PI355396 & $0.63 \pm 0.011$ & $1.68 \pm 0.09$ & $1.73 \pm 0.20$ & $2.01 \pm 0.10$ & $1.94 \pm 0.10$ \\
\hline PI358811 & $0.43 \pm 0.012$ & $0.43 \pm 0.02$ & $0.98 \pm 0.50$ & $1.65 \pm 0.11$ & $0.97 \pm 0.03$ \\
\hline PI368065 & $0.53 \pm 0.019$ & $0.75 \pm 0.03$ & $1.08 \pm 0.05$ & $1.57 \pm 0.09$ & $1.18 \pm 0.04$ \\
\hline PI368070 & $0.50 \pm 0.008$ & $0.95 \pm 0.03$ & $1.03 \pm 0.05$ & $1.70 \pm 0.06$ & $1.19 \pm 0.08$ \\
\hline PI368073 & $0.53 \pm 0.012$ & $1.55 \pm 0.08$ & $1.60 \pm 0.08$ & $1.75 \pm 0.06$ & $1.78 \pm 0.09$ \\
\hline PI368077 & $0.60 \pm 0.021$ & $1.15 \pm 0.09$ & $1.10 \pm 0.06$ & $1.93 \pm 0.08$ & $1.34 \pm 0.05$ \\
\hline PI368085 & $0.58 \pm 0.014$ & $1.68 \pm 0.10$ & $1.68 \pm 0.06$ & $2.29 \pm 0.06$ & $1.88 \pm 0.09$ \\
\hline PI438667 & $0.53 \pm 0.117$ & $2.23 \pm 0.18$ & $2.13 \pm 0.12$ & $1.72 \pm 0.10$ & $2.34 \pm 0.11$ \\
\hline PI439491 & $0.83 \pm 0.024$ & $1.13 \pm 0.04$ & $1.33 \pm 0.10$ & $1.61 \pm 0.07$ & $1.58 \pm 0.09$ \\
\hline PI439494 & $0.50 \pm 0.012$ & $1.85 \pm 0.14$ & $1.95 \pm 0.13$ & $2.29 \pm 0.11$ & $2.10 \pm 0.08$ \\
\hline PI439502 & $0.40 \pm 0.006$ & $2.87 \pm 0.25$ & $2.83 \pm 0.16$ & $1.20 \pm 0.08$ & $2.97 \pm 0.17$ \\
\hline PI439509 & $1.00 \pm 0.045$ & $1.18 \pm 0.15$ & $1.30 \pm 0.07$ & $1.67 \pm 0.06$ & $1.65 \pm 0.06$ \\
\hline PI439523 & $0.38 \pm 0.009$ & $1.95 \pm 0.15$ & $1.88 \pm 0.13$ & $1.93 \pm 0.08$ & $2.02 \pm 0.08$ \\
\hline PI441646 & $0.85 \pm 0.018$ & $1.28 \pm 0.06$ & $1.40 \pm 0.10$ & $1.51 \pm 0.07$ & $1.69 \pm 0.10$ \\
\hline PI543203 & $0.28 \pm 0.003$ & $2.70 \pm 0.21$ & $3.48 \pm 0.20$ & $0.74 \pm 0.05$ & $3.31 \pm 0.15$ \\
\hline PI585254 & $0.85 \pm 0.022$ & $1.20 \pm 0.07$ & $1.33 \pm 0.07$ & $1.77 \pm 0.08$ & $1.61 \pm 0.09$ \\
\hline PI585255 & $0.60 \pm 0.016$ & $1.33 \pm 0.09$ & $1.40 \pm 0.08$ & $1.45 \pm 0.08$ & $1.60 \pm 0.11$ \\
\hline PI585256 & $0.70 \pm 0.016$ & $2.58 \pm 0.20$ & $2.13 \pm 0.12$ & $1.66 \pm 0.05$ & $2.51 \pm 0.11$ \\
\hline PI593614 & $0.73 \pm 0.013$ & $1.05 \pm 0.06$ & $1.15 \pm 0.07$ & $1.30 \pm 0.07$ & $1.40 \pm 0.07$ \\
\hline PI593615 & $0.63 \pm 0.011$ & $1.68 \pm 0.07$ & $1.73 \pm 0.13$ & $1.80 \pm 0.10$ & $1.94 \pm 0.07$ \\
\hline PI594961 & $0.43 \pm 0.008$ & $2.37 \pm 0.18$ & $2.48 \pm 0.14$ & $1.03 \pm 0.05$ & $2.59 \pm 0.13$ \\
\hline PI631139 & $0.58 \pm 0.020$ & $0.85 \pm 0.07$ & $1.40 \pm 0.10$ & $1.63 \pm 0.05$ & $1.45 \pm 0.09$ \\
\hline PI631142 & $0.68 \pm 0.013$ & $0.53 \pm 0.03$ & $0.63 \pm 0.03$ & $1.43 \pm 0.06$ & $0.86 \pm 0.03$ \\
\hline GRIF9315 & $0.58 \pm 0.017$ & $3.18 \pm 0.28$ & $3.08 \pm 0.21$ & $1.63 \pm 0.10$ & $3.30 \pm 0.13$ \\
\hline GRIF9319 & $0.60 \pm 0.013$ & $1.28 \pm 0.08$ & $1.78 \pm 0.16$ & $1.74 \pm 0.09$ & $1.85 \pm 0.07$ \\
\hline GRIF9323 & $0.50 \pm 0.009$ & $1.20 \pm 0.06$ & $1.78 \pm 0.15$ & $1.76 \pm 0.13$ & $1.78 \pm 0.07$ \\
\hline GRIF9339 & $0.63 \pm 0.030$ & $2.23 \pm 0.16$ & $2.65 \pm 0.14$ & $1.41 \pm 0.08$ & $2.74 \pm 0.10$ \\
\hline
\end{tabular}

zPI numbers unless noted otherwise.

Eshbaugh, W.H. 1976. XII. Genetic and biochemical systematic studies of chile peppers ( $\mathrm{Cap}$ sicum - Solanaceae). Bull. Torrey Bot. Club 102:396-403.

Greenleaf, F.J., J.A. Martin, J.G. Lease, E.T. Sims, and L.O. van Blaircom. 1970. Greenleaf Tabasco, a new tobacco etch virus resistant 'Tabasco' pepper variety (Capsicum frutescens L.). Alabama Agr. Expt. Sta., Auburn University, Ala.

Harvell, K. and P.W. Bosland. 1997. The environment produces a significant effect on pungency of chiles. HortScience 32:1292.

Heiser, C.B., Jr. and B. Pickersgill. 1969. Names for the cultivated Capsicum species (Solanaceae). Taxon 18:277-283.

Heiser, C.B., Jr. and P.G. Smith. 1953. The cultivated Capsicum peppers. Eco. Bot. 7:214-226.

Iwai, K., T. Suzuki, and H. Fujiwake. 1979. Formation and accumulation of pungent principle of hot pepper fruits, capsaicin and its analogues, in Capsicum annuum var. annuum cv. Karayatsubusa at different growth stages after flowering. Agr. Biol. Chem. 43:2493-2498.

Jarret, R.L., B. Perkins, T. Fan, A. Prince, K. Guthrie, and B. Skoczenski. 2003. Using EIA to screen Capsicum spp. germplasm for cap- saicinoid content. J. Food Comp. Anal. 16:189 194.

Jarret, R.L., M. Spinks, G. Lovell, and A.G. Gillaspie. 1990. The S-9 plant germplasm collection at Griffin, Georgia. Diversity 6:23-25.

Krajewska, A.M. and J.J. Powers. 1988. Sensory properties of naturally occurring capsaicinoids. J. Food Sci. 53:902-905.

Lopez-Hernandez, J., M.J. Oruna-Concha, J. Simal-Lozano, M.E. Vazquez-Blanco, and M.J. Gonzalez-Castro. 1996. Chemical composition of Padron peppers (Capsicum annum (L.) grown in Galicia (N.W. Spain). Food Chem. 57:557-559.

Luning, P.A., R. van der Vuurst de Vries, D. Yuksel, T. Ebbenhorst-Seller, H.J. Wichers, and J.P. Roozen. 1994. Combined instrumental and sensory evaluation of flavor of fresh bell peppers (Capsicum annuum) harvested at three stages of maturity. J. Agr. Food Chem. 42:2855-2861.

Mathus, R., R.S. Dangi, S.C. Dass, and R.C. Malhotra. 2000. The hottest chili variety in India. Curr. Sci. 79:287-288.

Perkins, B., R. Bushway, K. Guthrie, T. Fan, B. Stewart, A. Prince, and M. Williams. 2002. Determination of capsaicinoids in salsa by liquid chromatography and enzyme immunoassay. JAOAC Int. 85:8285.

Smith, P.G. and C.B. Heiser, Jr. 1957. Taxonomy of Capsicum sinense Jacq. and the geographic distribution of the cultivated Capsicum spp. Bull. Torrey Bot. Club 84:413-420.

Suzuki, T. and K. Iwai. 1984. Constituents of red pepper species: Chemistry, biochemistry, pharmacology, and food science of the pungent principle of Capsicum species, p. 238-248. In: A. Brossi (ed.). The alkaloids: Chemistry and pharmacology. Academic, Orlando, Fla.

Zewdie, Y. and P.W. Bosland. 2000a. Capsaicinoid inheritance in an interspecific hybridization of Capsicum annuum $\mathrm{x}$ C. chinense. J. Amer. Soc. Hort. Sci. 125:448-453.

Zewdie, Y. and P.W. Bosland. 2000b. Pungency of chile (Capsicum annuum L.) is affected by node position. HortScience 35:1174

Zewdie, Y. and P.W. Bosland. 2001. Capsaicinoid profiles are not good chemotaxonomic indicators for Capsicum species. Biochem. Syst. Ecol. 29:161-169.

Zewdie, Y. and A.C. Zeven. 1997. Variation in Yugoslavian hot pepper (Capsicum annuum L.) accessions. Euphytica. 97:81-89. 